\title{
Technical note: Evaluation of 3 methods to determine mucin protein concentration in ileal digesta of young preweaning calves
}

\author{
I. Ansia 10 and J. K. Drackley* (i) \\ Department of Animal Sciences, University of Illinois, Urbana 61801
}

\begin{abstract}
The use of alternative sources of protein to substitute for milk proteins in milk replacers (MR) can increase the synthesis of endogenous proteins and therefore alter ileal or total-tract digestibility calculations. Mucin is the main component of gastrointestinal mucus and represents the greatest contribution to total endogenous protein. Mucin is difficult to isolate and has not been extensively studied in dairy calves. We explored 3 different procedures to analyze and estimate mucin protein (MUP) in ileal digesta of young dairy calves. Ileal digesta samples were collected from nine 30-d-old ileal-cannulated calves that were enrolled in a $3 \times 3$ replicated Latin square with 5 -d periods. The 3 diets were a control whey protein-based MR (WPC), an isonitrogenous $\mathrm{MR}$ in which $50 \%$ of the protein was from enzyme-treated soybean meal (ESBM), and an N-free MR (NFREE). Mucin protein concentration and flow were analyzed by fractionation of the digesta and ethanol precipitation; this process served as the reference method. Alternative methods to estimate MUP consisted of using commercial enzymatic kits to analyze glucosamine ( $N$-acetylglucosamine, GlcNAc) and galactosamine ( $N$-acetylgalactosamine, GalNAc), 2 amino-sugars that are highly enriched in mucin. Before GlcNAc determination, samples were processed using 3 different procedures: sample clarification (GLCL), clarification plus hydrolysis (GLCH), and hydrolysis alone (GLHL). The MUP was estimated by regression of the GlcNAc and GalNAc values using previously validated equations. According with the bias and agreement analysis, none of the methods yielded MUP values similar to the reference method. However, GLHL showed a strong association with the reference method $(\rho=0.73)$. It allowed identifying the smaller MUP flows with NFREE compared with the other 2 diets and detecting the greater flow of ESBM than WPC, as
\end{abstract}

Received December 24, 2019

Accepted February 2, 2020.

*Corresponding author: drackley@illinois.edu observed with the reference method. Using the GlcNAc values from GLHL and the MUP measured with the reference method, we were able to establish a linear relationship between both methods (adjusted $\mathrm{R}^{2}=0.75$ ). We found that the GLHL method enabled detecting differences in MUP ileal flows between diets differing in protein level and source. Inferences about MUP secretions must be done cautiously because many dietary and physiological factors are involved. The adoption of practical techniques to determine MUP can help to increase our knowledge about gastrointestinal tract function and to improve the accuracy of MR digestibility calculations.

Key words: calf, endogenous protein, mucin, digestibility

\section{Technical Note}

The nutritional value of milk or milk replacer (MR) is largely determined by the content of bioavailable protein (Drackley, 2008). Plant proteins and especially soy proteins are among the most studied alternatives to milk proteins in MR because of their lower price. However, the presence of antinutritional factors can impair growth and health (Lallés, 1993), especially in the first weeks of life due to the lack of significant rumen fermentation (Barratt et al., 1978; Tukur et al., 1993). Among other effects, antinutritional factors react with the gut mucosa to stimulate the secretion of mucus from goblet cells in the small intestinal epithelium (Schulze et al., 1995; Montagne et al., 2000a), which creates the first line of defense against physical and chemical damage (Kim and Ho, 2010). In addition, resistant dietary proteins (Santoro et al., 1999), fiber (Mariscal-Landín et al., 1995), and other factors, such as BW, DMI, bacterial infections, host intestinal flora, and weaning, can affect the endogenous secretion of mucus (Brown et al., 2006; Kim and Ho, 2010; Nyachoti et al., 1997).

Mucin is a heavily glycosylated protein that constitutes the main component of gastrointestinal mucus. Its protein content can range between 53 and $21 \%$ of the whole molecule weight in calves and pigs, respectively (Mantle and Allen, 1981; Montagne et al., 2000b). Each 
mucin monomer contains a central region where $\mathrm{N}$ acetylgalactosamine (GalNAc) bonds to a Thr or Ser residue (Bansil et al., 1995). This region is surrounded by oligosaccharides that protect it from proteases (Bansil et al., 1995) and mucin protein (MUP) is therefore not completely digested once it reaches the ileum (Montagne et al., 2001). Mucin protein represents the biggest contribution to endogenous $\mathrm{N}$ losses, and if it is not quantified, the ileal digestibility of feed ingredients and diets can be underestimated (Fuller and Cadenhead, 1991; Montagne et al., 2003). Losses of MUP represent $11 \%$ in pigs and $19 \%$ in calves of the basal endogenous losses; however, contributions of individual AA can represent up to 40 and $29 \%$ of Lys and Glu, respectively, in calves, and up to 35 and $24 \%$ of $\mathrm{Thr}$ and Pro, respectively, of the AA losses in pigs (Lien et al., 1997; Montagne et al., 2000a). Determination of MUP can be a suitable proxy to look at differences in endogenous protein losses in digesta or feces when comparing ileal or total-tract $\mathrm{N}$ output and digestibility between different protein sources (Montagne et al., 2000a).

Direct determination of MUP concentration in digesta can be achieved with ELISA, Western blotting, and immunohistochemistry, among other techniques (Harrop et al., 2012). However, these techniques are laborious and require specialized equipment. The ethanol precipitation method seems to be a reliable and simple procedure, but it requires a considerable amount of digesta or feces (2.5 to $3 \mathrm{~g})$ and consequently might not always be practical (Piel et al., 2004; Miner-Williams et al., 2012). On the other hand, MUP concentration can be extrapolated from the concentration of the hexoamines $\mathrm{N}$-acetylglucosamine (GlcNAc) and especially GalNAc because of their limited presence in other endogenous or dietary sources (Lien et al., 1997). Different experiments have been conducted to establish a linear regression equation to predict MUP output from the digesta concentrations of GalNAc and GlcNAc (Lien et al., 1997; Montagne et al., 2000a). To our knowledge, GalNAc and GlcNAc concentrations have only been measured by ion-exchange chromatography, another expensive and time-consuming technique. More data on endogenous protein secretions are needed to better understand the interaction of dietary proteins with the intestinal mucosa in young dairy calves and to provide accurate values for digestibility of MR.

To facilitate and expand data collection, we explored the performance of 3 different commercially available methods for the indirect determination and comparison of MUP content in ileal digesta of preweaning calves. The methods were determination of total GlcNAc concentration by absorbance spectroscopy, determination of GalNAc by fluorescence spectroscopy, and determination of MUP content by ethanol precipitation.
Ileal digesta samples used in these analysis were derived from a previous digestibility experiment by our group (Ansia et al., 2020). Briefly, at approximately $30 \mathrm{~d}$ of age, 9 ileal-cannulated calves were randomly assigned to a 3 (periods) $\times 3$ (calves) triplicated Latin square with 5 -d periods. Calves were fed twice daily at a rate of $2 \%(\mathrm{DM})$ of $\mathrm{BW}$, adjusted weekly. To minimize rumen development, no solid food was offered. Digesta samples were collected continuously by attaching a 250-mL plastic bag to the cannula with an autolocking cable tie after removing the cannula cap for $12 \mathrm{~h}$ on d 4 and 5 of each period. Bags were removed when full or approximately every $30 \mathrm{~min}$, placed in a cooler with ice, and the totality of the digesta collected was immediately frozen and composited by calf and period. Digesta was thawed at room temperature and mixed, and a representative subsample was collected and refrozen for further analysis. The 3 experimental diets were a control MR with whey protein concentrate as the only source of protein (WPC), an isonitrogenous $\mathrm{MR}$ in which $50 \%$ of the protein was provided with an enzyme-treated soybean meal (ESBM; HP-100, Hamlet Protein A/S, Horsens, Denmark), and an N-free MR (NFREE) to determine basal endogenous protein losses. Chromic oxide (0.2\%, DM basis) was fed with the $\mathrm{MR}$ as indigestible marker for the solid phase of the digesta, and the complex Cobalt-Na-EDTA $(0.85 \%$, DM basis) was used as marker for the liquid phase. The average of the recovered concentrations of both markers was used to calculate digesta flows at the ileum relative to DMI.

First, free and total GlcNAc (including D-glucosamine-6-sulfate, D-glucosamine-2-sulfate, and $\mathrm{N}$-acetyl D-glucosamine) concentration was determined in freezedried digesta using a commercial enzymatic assay kit for food and nutraceutical preparations (Megaenzyme International, Bray, Ireland) and a microplate spectrophotometer reader (Epoch, BioTek, Winooski, VT) at a wavelength of $340 \mathrm{~nm}$. Briefly, in this method, D-glucosamine is first phosphorylated to glucosamine6-phosphate, which is then deaminated, yielding fructose-6-phosphate, which is converted to glucose6 -phosphate. The increase in absorbance is used to measure the amount of NADPH formed during the oxidation of glucose-6-phosphate because it is stoichiometric with the amount of initial D-glucosamine. Before addition of any reagent in the current study, samples were prepared using 3 different methods: sample clarification (GLCL) for free GlcNa, clarification plus hydrolysis (GLCH), and direct hydrolysis of the solid sample (GLHL) for total GlcNa. For the clarification and hydrolysis procedures, instructions from the assay manufacturer were followed. For the GLCL method, $4 \mathrm{~g}$ of freeze-dried sample were initially dissolved in $80 \mathrm{~mL}$ 
of Milli-Q water. With continuous mixing, $5 \mathrm{~mL}$ of Carrez I solution $\left\{3.60 \mathrm{~g}\right.$ of $\mathrm{K}_{4}\left[\mathrm{Fe}(\mathrm{CN})_{6}\right] \cdot 3 \mathrm{H}_{2} \mathrm{O}$ in $100 \mathrm{~mL}$ of Milli-Q water $\}, 5 \mathrm{~mL}$ of Carrez II solution $(7.20 \mathrm{~g}$ of $\mathrm{ZnSO}_{4} \cdot 7 \mathrm{H}_{2} \mathrm{O}$ in $100 \mathrm{~mL}$ of Milli-Q water), and $10 \mathrm{~mL}$ of $\mathrm{NaOH}$ solution $(100 \mathrm{~m} M)$ were added to the solution. A $15-\mathrm{mL}$ aliquot was centrifuged $(1,050 \times g$ for $2 \mathrm{~min}$ at room temperature), and $1 \mathrm{~mL}$ of the supernatant was transferred into a new microtube. In the case of the GLCH pretreatment, a further $1 \mathrm{~mL}$ of $4 \mathrm{M} \mathrm{HCl}$ was added. After incubation in a water bath at $110^{\circ} \mathrm{C}$ for $2 \mathrm{~h}$, the solution was neutralized with $2 \mathrm{~mL}$ of $2 M$ $\mathrm{NaOH}$. For the GLHL method, between 10 and $30 \mathrm{mg}$ of freeze-dried digesta (depending on the $\mathrm{CP}$ content of the sample) was hydrolyzed in $2 \mathrm{~mL}$ of $5 \mathrm{M} \mathrm{HCl}$ for $2 \mathrm{~h}$ at $110^{\circ} \mathrm{C}$, following the process described by Montagne et al. (2000a). Samples from GLCH and GLHL were centrifuged $(1,050 \times g$ for 2 min at room temperature) to eliminate any residue and obtain a clear sample solution.

Galactosamine concentration was determined using a commercial assay kit for fecal mucin following the manufacturer's instructions (Cosmo Bio Co. Ltd., Tokyo, Japan). After extraction of mucin by this method, the GalNAc chains that are o-glycosidically linked within the mucin domain are $\beta$-eliminated by diluted alkali. The formed reducing end of GalNAc reacts with 2-cyanoacetamide at high temperature to produce intensely fluorescent condensates (Crowther and Wetmore, 1987). In the current study, fluorescence was read with a measurement wavelength of $330 \mathrm{~nm}$ for excitation and $420 \mathrm{~nm}$ for emission using an Analyst HT (LJL BioSystems Inc., Sunnyvale, CA).

Determination of MUP by ethanol precipitation was accomplished after fractionation of the digesta by centrifugation (Miner-Williams et al., 2012). Freeze-dried digesta was reconstituted (1:20, wt/vol at room temperature $)$ in saline solution $(0.15 \mathrm{~mol} / \mathrm{L})$. First, digesta was centrifuged at $250 \times g$ for $15 \mathrm{~min}$ at $4^{\circ} \mathrm{C}$. This precipitate was expected to contain food debris and intact mucosal cells. Supernatant was then centrifuged at $14,500 \times g$ for $30 \mathrm{~min}$ at $4^{\circ} \mathrm{C}$. This second precipitate was expected to contain microbial cells, whereas the supernatant was expected to contain soluble $\mathrm{N}$ components. The supernatant was mixed with ethanol $\left(1: 1.5, \mathrm{vol} / \mathrm{vol}\right.$ at $\left.0^{\circ} \mathrm{C}\right)$, kept overnight at $-20^{\circ} \mathrm{C}$, and centrifuged at $1,400 \times g$ for $10 \mathrm{~min}$ at $4^{\circ} \mathrm{C}$. The crude mucin precipitate was recovered in $15 \mathrm{~mL}$ of saline solution and precipitated again with ethanol in the same conditions. The 3 precipitates were recovered in $10 \mathrm{~mL}$ of the saline solution, freeze-dried, and weighed (Piel et al., 2004; Montoya et al., 2015). Crude protein content in the final crude mucin precipitate was analyzed by the combustion method (AOAC International, 2006; method 990.03).
Even though fractionation and precipitation of glycoprotein is a rather nonspecific method, it performs optimally compared with other more specific assays such as ELISA (Piel et al., 2004), and therefore, it will be considered our method of reference in this technical note. Mucin protein concentrations were extrapolated from GlcNAc and GalNAc concentrations from each of the alternate methods using the regression equations reported by Montagne et al. (2000a). Comparisons between diets for MUP concentrations and flows were performed using PROC MIXED procedure in SAS version 9.4 (2012; SAS Institute Inc., Cary, NC ) with diet and period as fixed factors and calf as a random effect. The $P$-values for the comparisons among the 3 diets were adjusted by the Tukey-Kramer method. In addition, the WPC and ESBM diets were compared using orthogonal contrasts with the CONTRAST statement within PROC MIXED. To account for the carry-over effect, a set of variables representing the sequence of treatments were included as covariates. Assumptions about the normality and homogeneity of residuals derived from the analyses of variance were checked using the PROC UNIVARIATE procedure and the INFLUENCE option within PROC MIXED in SAS. The association and agreement between ileal MUP output obtained with the reference method and that obtained with all the hexosamine methods were evaluated using Pearson's and Lin's concordance correlations (Lin, 1989), respectively. Bias between the measurements was evaluated using Bland-Altman plots (Bland and Altman, 1986).

The MUP concentration values obtained with the reference method manifested the influences of diets and were greater with the WPC and ESBM than with NFREE (Table 1). Only the GLHL method yielded values that manifested the same effect of the diets. Although the GLCL values showed no diet effect, the GLCH method showed a greater MUP concentration with NFREE than with the other 2 diets. Unlike any of the methods based on GlcNAc concentrations, extrapolation of MUP using GalNAc concentrations with Montagne's equation resulted in the greatest MUP concentration for digesta from the WPC diet. Only the flows of MUP obtained with the reference method demonstrated a lower flow with NFREE than the other 2 diets. In contrast, MUP flows with the GLCL method were not influenced by diet, and GLCH and GalNAc showed greater flows with NFREE than with the other diets. Only the GLHL method could identify a greater MUP flow with the ESBM diet in comparison with WPC, as observed with the reference method.

Comparison of the different methods within each diet indicates that the NFREE diet showed the most similarities between methods (Table 1). The NFREE diet 
Table 1. Least squares means of mucin protein concentrations and flows analyzed with the reference method (ethanol precipitation) and estimated from glucosamine and galactosamine concentrations

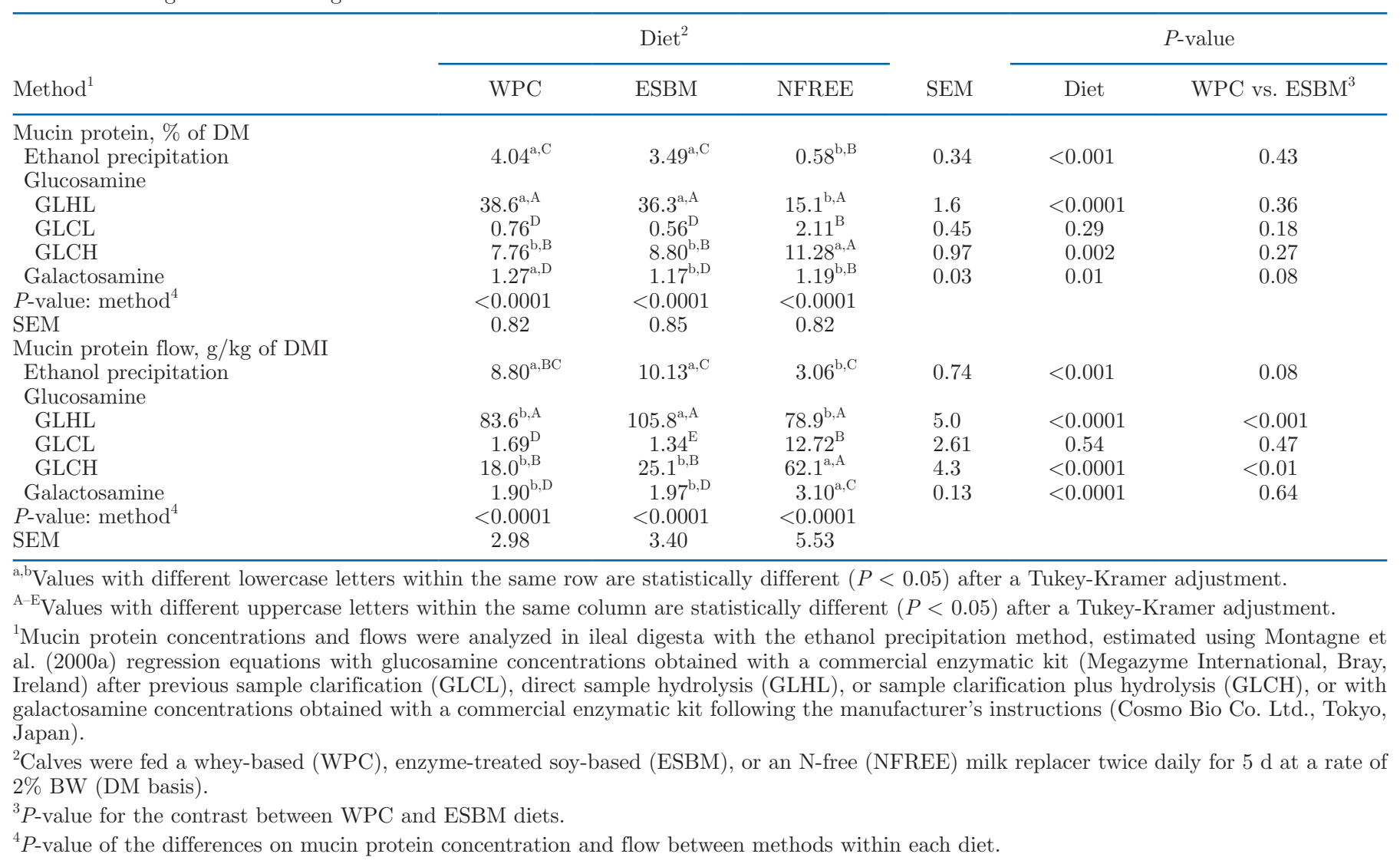

had MUP concentrations that did not differ between GLCL, GalNa, and the reference method. Regarding MUP flows, only the flow estimated with GalNAc was not different from that of the reference method during the NFREE diet. No other method showed values similar to those of the reference method during the WPC and ESBM diets. Overall, GLHL always showed the highest values, whereas GLCL and GalNAc showed the lowest.

Pearson correlation analysis of the MUP concentrations showed that the strongest association was between the reference method and values obtained with GLHL (Table 2), with GalNAc having the second greatest correlation coefficient among all methods. Coefficients for GLCH were negative and no significant correlation with GLCL was observed. The correlation coefficient of the MUP flow was highest with GLHL as well, but lower than that obtained between the concentration values. The rest of the coefficients for MUP flows were all significant but negative, indicating an undesirable association for our objective. The Lin's concordance correlation coefficient (CCC) quantifies the agreement between 2 measures of the same variable and ranges between -1 (perfect disagreement) and 1 (perfect agreement). The CCC between the reference method and both GLHL and GalNAc methods for ileal MUP concentration were the highest among all methods. However, a value of 0.04 represents only a minimal agreement between methods. The CCC values for the remaining methods for either concentration or flow were lower, indicating even worse agreement. The GLCL method showed the biggest disagreement among all with a value of -0.46 .

The Bland-Altman plot (Figure 1) is a graphical method to assess bias where the differences between values from 2 techniques are plotted against the mean values of both. In a comparison with the reference method, values of MUP concentration and flows manifested a relatively small positive bias with GLCL $(+1.7$ and +2.4$)$ and GalNAc $(+1.5$ and +5.0$)$. On the other hand, values from GLHL $(-27$ and -82$)$ and GLCH $(-7$ and -27$)$ showed a stronger negative bias for MUP concentration and flow. All methods exhibited a case of proportional error, with the difference increasing along with the mean value. Only GLCH had $100 \%$ of their MUP concentration values lying within the limits of agreement $( \pm 1.96$ times the standard deviation of the differences). The value for concentrations and flows 
with GLHL and GalNAc decreased to $96 \%$, and to $92 \%$ with GLCL and with the flows of GLCH.

Despite a substantially lower MUP concentration during the NFREE diet (2.58\% of digesta DM), MUP flows (i.e., basal flow of mucin) obtained with the reference method were similar $(3.97 \mathrm{~g} / \mathrm{kg} \mathrm{DMI})$ to values reported by Montagne et al. (2000a) and also with those found in pigs $(3.8 \mathrm{~g} / \mathrm{kg}$ DMI $)$ by Lien at al. (1997). However, in our study we did identify a significant increase in MUP concentration when dietary CP increased by inclusion of whey protein. In the study by Montagne et al. (2000a), skim milk was the only source of milk protein, and the different AA profile between skim milk and whey proteins may have caused the different mucin output rate (Montagne et al., 2000b). In addition, the lower digestibility of the milk protein diet found in our study in comparison with Montagne et al. (2001) may also have increased the rate of mucin secretion due to a greater flow of undigested protein fractions (Ansia et al., 2020). Flows of MUP as determined by the reference method in our study were also in close agreement with those reported by Montagne et al. (2000a), who substituted milk proteins with soy protein by up to $50 \%$ (soy protein concentrate and hydrolyzed isolate). Despite the lower specificity of the ethanol precipitation method compared with an ELISA, it shows a smaller variability that provides greater sensitivity to detect differences in MUP between dietary protein sources (Piel et al., 2004).

Based on the bias and agreement analysis, values of GlcNAc and GalNAc obtained with the methods explored on this note are not suitable to yield accurate estimations of MUP concentrations with Montagne's regression equation. Our total GlcNAc values with the GLCH method were $19.2 \pm 2.3$ and $21.6 \pm 2.2 \mathrm{~g} / \mathrm{kg}$ of digesta DM for the WPC and ESBM diets, respectively. These values were greater than those obtained by ionexchange chromatography (Montagne et al., 2000a) but did not show a pattern of proportional error as evident as the other methods explored in this note when used to extrapolate MUP concentrations. On the other hand, free GlcNAc (GLCL) values were $2.6 \pm 1.0$ and $2.2 \pm$ $1.0 \mathrm{~g} / \mathrm{kg}$ digesta DM for the WPC and ESBM diets, respectively, and were lower but in a closer agreement with Montagne et al. (2000a) as shown by the Bland-Altman plots (Figure 1a). Nevertheless, both methods failed to identify the greatest differences in MUP concentration of the NFREE diet and therefore yielded estimations with a very high disagreement and no association with the reference method used in our experiments. Carrez clarification was performed in samples containing protein, as suggested by the manufacturer. This method precipitates protein, eliminates turbidity of the sample solution, and breaks emulsions that may interfere with

Table 2. Pearson and Lin concordance correlation coefficients and $P$-values between mucin protein concentrations and flows analyzed with the reference method (ethanol precipitation) and estimated from glucosamine and galactosamine concentrations

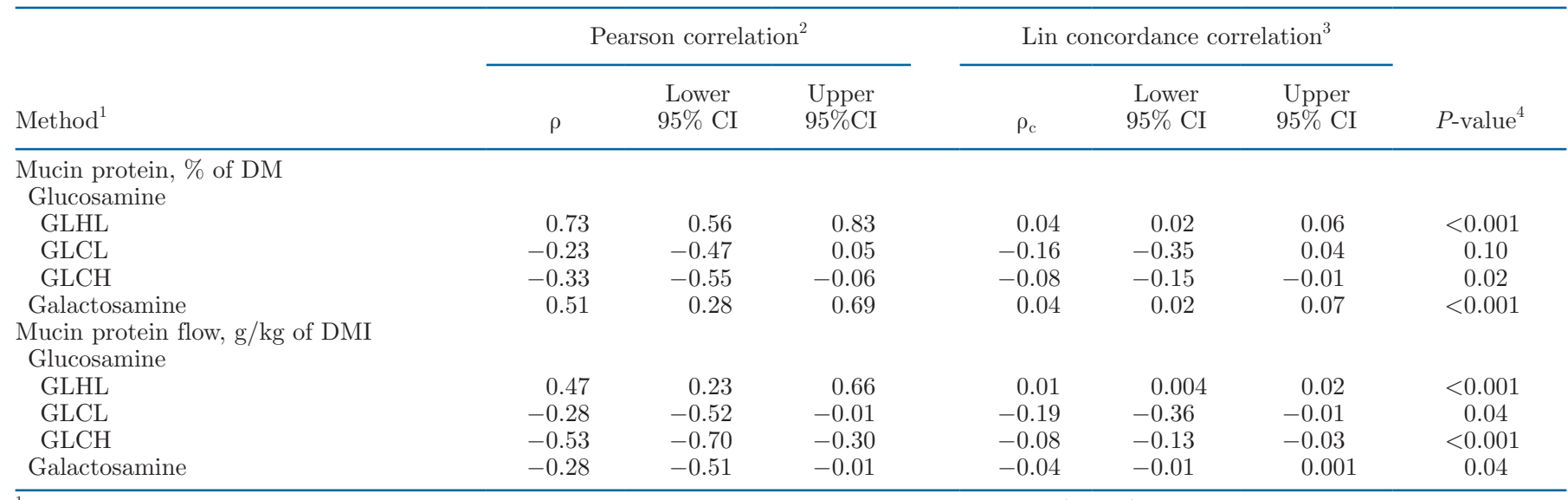

${ }^{1}$ Mucin protein concentrations and flows were estimated in ileal digesta using Montagne et al. (2000a) regression equations with glucosamine concentrations obtained with a commercial enzymatic kit (Megazyme International, Bray, Ireland) by previous sample clarification (GLCL), direct sample hydrolysis (GLHL), or sample clarification plus hydrolysis (GLCH), or with galactosamine concentrations obtained with a commercial enzymatic kit following the manufacturer's instructions (Cosmo Bio Co. Ltd., Tokyo, Japan).

${ }^{2}$ Pearson correlation coefficient $(\rho)$ and $95 \%$ CI bounds for the association between mucin concentrations and flows analyzed with the reference method (ethanol precipitation) and estimated values using Montagne et al. (2000a) regression equation with glucosamine and galactosamine values.

${ }^{3}$ Lin concordance correlation coefficient $\left(\rho_{\mathrm{c}}\right)$ and $95 \%$ CI bounds for the association between mucin concentrations and flows analyzed with the reference method (ethanol precipitation) and estimated values using Montagne et al. (2000a) regression equation with glucosamine and galactosamine values.

${ }^{4} P$-value of the correlation between the reference (ethanol precipitation) and alternative methods (glucosamine and galactosamine concentration). 
GlcNAc determination. However, the Carrez salt solutions might have caused precipitation of some of the glycoproteins (Beeley, 1985) and therefore might have reduced the GlcNAc available for later determination. In fact, GlcNAc concentration values in digesta with the NFREE diet, where the glycoprotein concentration is presumably the lowest, were very close to values from the GLCH and GLCL methods (Table 1), where the only difference is the previous clarification step.

Galactosamine concentrations averaged $1.1 \pm 0.1 \mathrm{~g} /$ $\mathrm{kg}$ of digesta DM for the 3 diets. This value is considerably lower than values reported previously for calves and pigs (Montagne et al., 2000a; Piel et al., 2004). During GalNAc analysis, resolution of the precipitate

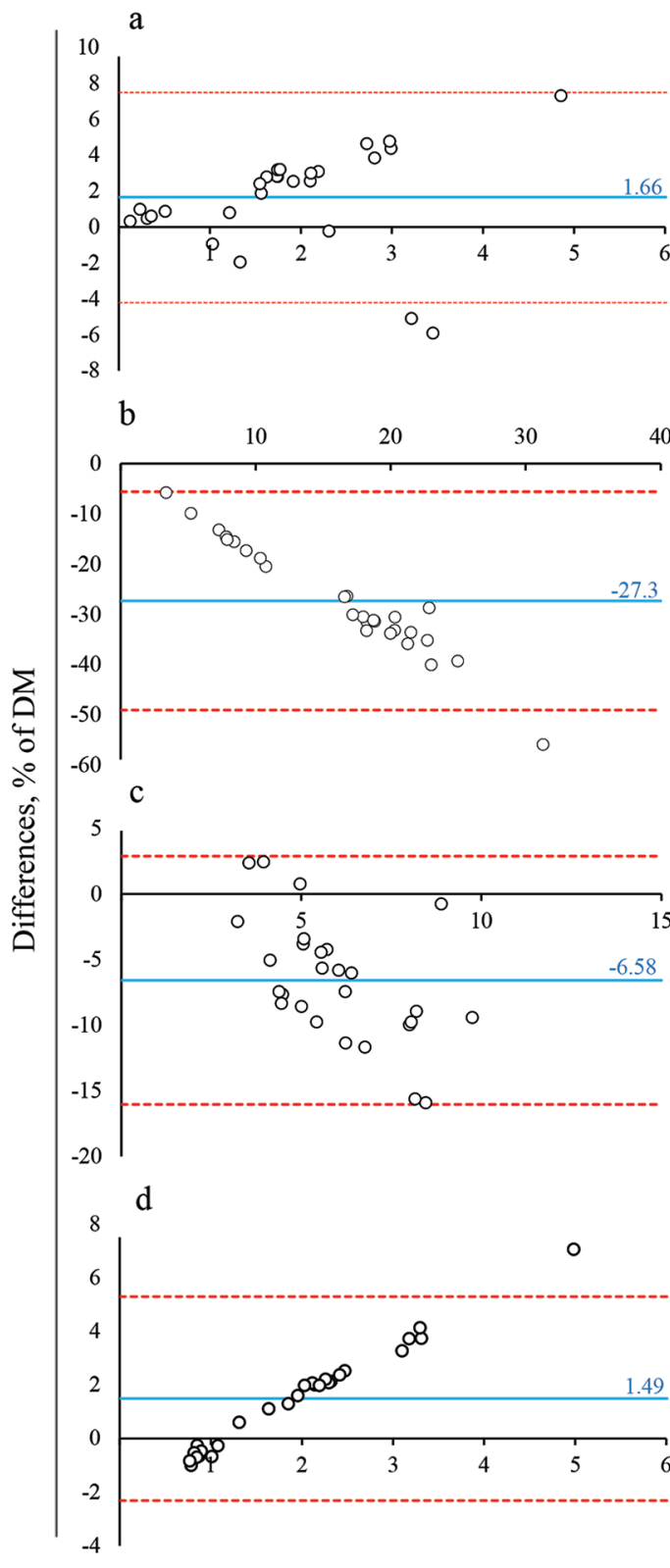

Means, \% of DM

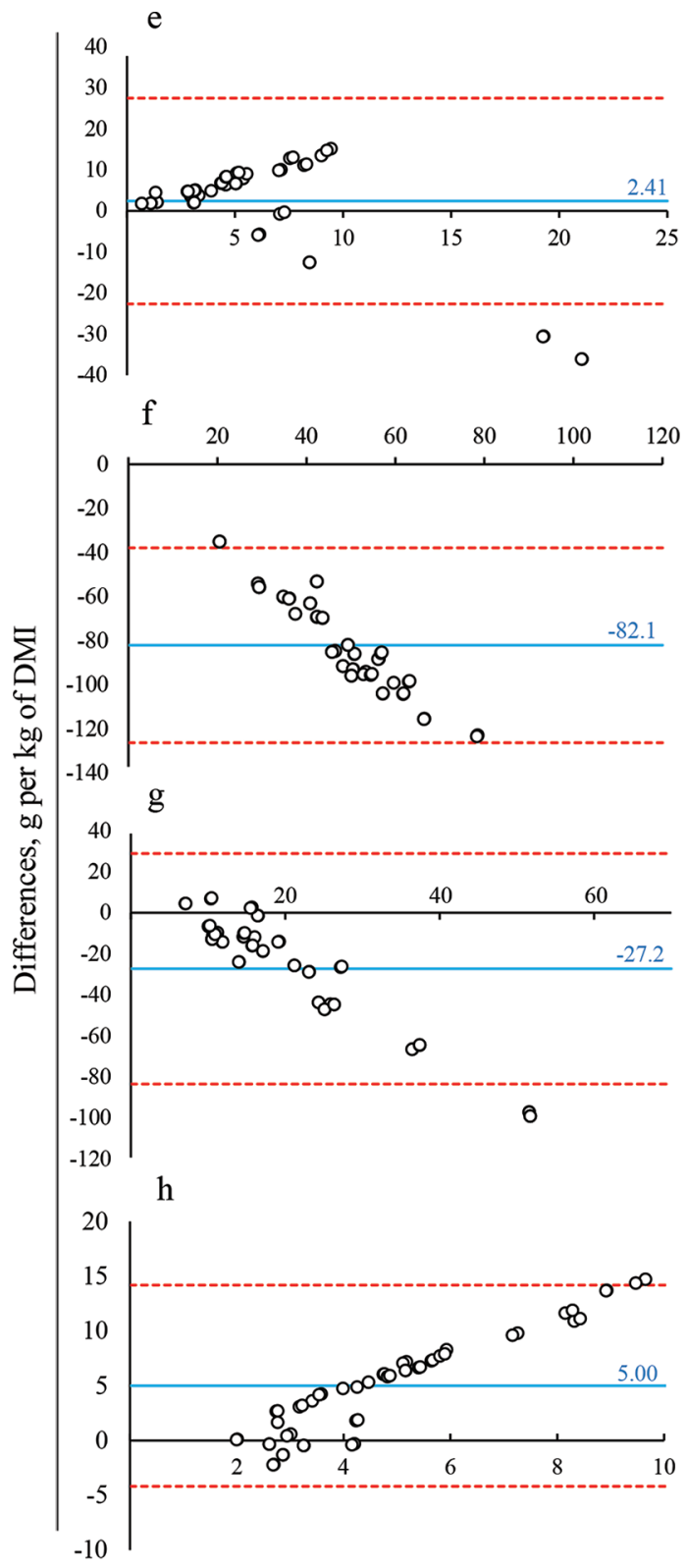

Means, g per kg of DMI

Figure 1. Bland-Altman plot of differences in mucin protein concentrations (a-d) and flows (e-h) analyzed with the reference method (ethanol precipitation) and estimated using Montagne et al. (2000a) regression equations with glucosamine concentrations obtained with a commercial enzymatic kit (Megazyme International, Bray, Ireland) by previous sample clarification (a and e), direct sample hydrolysis (b and f), and sample clarification plus hydrolysis (c and $\mathrm{g}$ ), and with galactosamine concentrations ( $\mathrm{d}$ and $\mathrm{h}$ ) obtained with another commercial kit following the manufacturer's instructions (Cosmo Bio Co. Ltd., Tokyo, Japan) in ileal digesta. The solid blue represents the mean (bias); the upper and lower red dotted lines show the limit of agreement (bias $\pm 1.96 \mathrm{SD}$ ), and the solid black line indicates bias $=0$. 
after ethanol precipitation was a critical step, but obtaining a homogeneous solution was difficult. The commercial kit used for GalNAc determination is designed for use with fecal samples and therefore the greater glycoprotein or fat content in digesta relative to feces might have affected the recovery and resolubilizing of the precipitate pellet. Mechanical homogenization may be required in that step for a better performance.

Mucin protein precipitation with ethanol is not specific to mucin and may have an important coefficient of variation depending on the accuracy of the final ethanol volumes (Miner-Williams et al., 2013). Highly glycosylated glycoproteins are difficult to precipitate and will remain soluble in high concentrations of ethanol due to the intermolecular associations and with glycosylated fibrous proteins that affect their molecular density (Beeley, 1985; Miner-Williams et al., 2013). However, calf digesta mucin has a low proportion of carbohydrates (Montagne et al., 2000b) relative to protein (carbohydrate:protein $=0.90$ ) in comparison with pig's mucin (1.04 to 3.28; Lien et al., 1997; Miner-Williams et al., 2013) and can be more easily precipitated.

Even within the same species (pigs) and using the same method of ethanol precipitation, recovery of $\mathrm{CP}$ from the precipitate has yielded very different results (14 to 35\% CP; Lien et al., 1997; Miner-Williams et al., 2013). In our study, the CP content of the recovered precipitate by the reference method across diets was $26 \%$ of digesta DM, while pure ileal calf mucin has a content of $53 \%$ CP (Montagne et al., 2000b). Not only may the protein composition of the recovered mucin vary according to the diet, but it can also change depending on the proportional contribution of mucin forms that reach the ileum from different sites of the gastrointestinal tract (Lien et al., 1997). Moreover, solubility of glycoproteins will increase if they have been degraded to the mucin subunits, and the solubility will also depend on $\mathrm{pH}$ and the presence of bile acids (Beeley, 1985; Lien et al., 1997). Basal endogenous losses of mucin and other endogenous proteins are also influenced by physiological, dietary, and genetic factors and are therefore specific for the animals and the experimental design selected (Stein et al., 2007). Basal endogenous protein losses must therefore be measured routinely to compare the effect of different diet compositions on mucin secretions and their effect on apparent ileal digestibilities within a specific experimental setting (Hess and Sève, 1999). Selecting the correct method to estimate MUP flows can have a pronounced effect on the calculations of feed ileal digestibilities. The average apparent ileal digestibility of WPC and ESBM $(71.9 \pm 2.2 \%)$ after being adjusted for the flows of MUP can increase to $72.4,75.3$, or 79.7 depending if the method used was GLCL, the reference method, or GLCH, respectively.

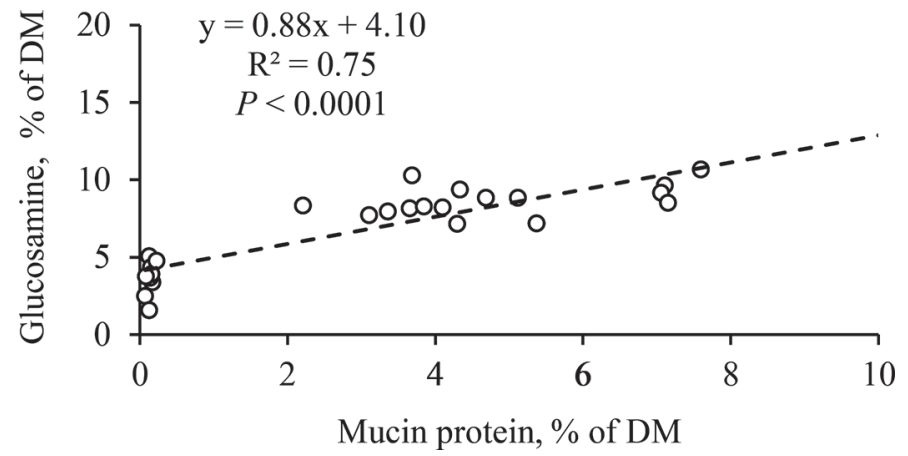

Figure 2. Relationship between the concentrations of mucin protein obtained with the reference method (ethanol precipitation) and glucosamine concentrations measured after direct sample hydrolysis (GLHL) in ileal digesta across diets $(n=9)$.

Direct hydrolysis of frozen digesta samples as described by Montagne et al. (2000b) resulted in very high yields of GlcNa. Because the kit used for this component is designed for food or nutraceutical samples, the presence of other biological constituents in ileal digesta samples might have interfered in the absorbance reading. However, total GlcNAc values with GLHL enabled identifying the same differences as the reference method and both showed a strong association, as documented by the Pearson correlation. Therefore, we were able to create an updated linear regression equation to extrapolate mucin protein concentrations from the total GlcNAc values obtained with the GLHL method (Figure 2).

Estimation of MUP using a commercially available enzymatic kit for total GlcNAc following previous sample hydrolysis is a suitable tool for measuring and comparing the effect of different dietary CP levels and MR ingredients on MUP flow. Values obtained can be compared favorably with results from the nonspecific ethanol precipitation method used as a reference.

\section{ACKNOWLEDGMENTS}

The experiment was supported by unrestricted funds provided to the University of Illinois. Ivan Ansia was supported by the Jimmy Clark Fellowship in Applied Dairy Cattle Nutrition. The authors have not stated any conflicts of interest.

\section{REFERENCES}

Ansia, I., H. H. Stein, D. A. Vermeire, C. Brøkner, and J. K. Drackley. 2020. Ileal digestibility and endogenous protein losses of milk replacers based on whey proteins alone or with an enzyme-treated soybean meal in young dairy calves. J. Dairy Sci. 103:4390-4407. https://doi.org/10.3168/jds.2019-17699.

AOAC International. 2006. Official Methods of Analysis. 18th ed. AOAC International, Gaithersburg, MD. 
Bansil, R., E. Stanley, and J. T. LaMont. 1995. Mucin biophysics. Annu. Rev. Physiol. 57:635-657. https://doi.org/10.1146/annurev .ph.57.030195.003223.

Barratt, M. E., P. J. Strachan, and P. Porter. 1978. Antibody mechanisms implicated in digestive disturbances following ingestion of soya protein in calves and piglets. Clin. Exp. Immunol. 31:305-312.

Beeley, J. G. 1985. Isolation and fractionation. Pages 29-62 in Laboratory Techniques in Biochemistry and Molecular Biology: Glycoprotein and Proteoglycan Techniques. Elsevier Science Publishers, Amsterdam, the Netherlands. https://doi.org/https://doi:10 .1016/S0075-7535(08)70226-2.

Bland, J. M., and D. G. Altman. 1986. Statistical methods for assessing agreement between two methods of clinical measurement. Lancet 327:307-310. https://doi.org/10.1016/S0140-6736(86)90837-8.

Brown, D. C., C. V. Maxwell, G. F. Erf, M. E. Davis, S. Singh, and Z. B. Johnson. 2006. The influence of different management systems and age on intestinal morphology, immune cell numbers and mucin production from goblet cells in post-weaning pigs. Vet. Immunol. Immunopathol. 111:187-198. https://doi.org/10.1016/j.vetimm 2005.12.006.

Crowther, R. S., and R. F. Wetmore. 1987. Fluorometric assay of Olinked glycoproteins by reaction with 2-cyanoacetamide. Anal. Biochem. 163:170-174. https://doi.org/10.1016/0003-2697(87)90108 -4 .

Drackley, J. K. 2008. Calf nutrition from birth to breeding. Vet. Clin. North Am. Food Anim. Pract. 24:55-86. https://doi.org/10.1016/ j.cvfa.2008.01.001.

Fuller, M. F., and A. Cadenhead. 1991. Effect of the amount and composition of the diet on galactosamine flow from the small intestine. Pages 331-333 in Digestive Physiology in Pigs. Proceedings of the Vth International Symposium on Digestive Physiology in Pigs. European Association of Animal Production, Wageningen, the Netherlands.

Harrop, C. A., D. J. Thornton, and M. A. McGuckin. 2012. Detecting, visualising, and quantifying mucins. Pages 49-66 in Mucins. Methods in Molecular Biology (Methods and Protocols). Vol. 842. M. A. McGuckin and D. J. Thornton, ed. Humana Press, Totowa, NJ.

Hess, V., and B. Sève. 1999. Effects of body weight and feed intake level on basal ileal endogenous losses in growing pigs. J. Anim. Sci. 77:3281-3288. https://doi.org/10.2527/1999.77123281x.

Kim, Y. S., and S. B. Ho. 2010. Intestinal goblet cells and mucins in health and disease: Recent insights and progress. Curr. Gastroenterol. Rep. 12:319-330. https://doi.org/10.1007/s11894-010-0131 -2 .

Lallés, J. P. 1993. Nutritional and antinutritional aspects of soyabean and field pea proteins used in veal calf production: A review. Livest. Prod. Sci. 34:181-202. https://doi.org/10.1016/0301 -6226(93)90106-R

Lien, K. A., W. C. Sauer, and M. Fenton. 1997. Mucin output in ileal digesta of pigs fed a protein-free diet. Z. Ernahrungswiss. 36:182-190. https://doi.org/10.1007/bf01611398.

Lin, L. I.-K. 1989. A concordance correlation coefficient to evaluate reproducibility. Biometrics 45:255-268. https://doi.org/10.2307/ 2532051.

Mantle, M., and A. Allen. 1981. Isolation and characterization of the native glycoprotein from pig small-intestinal mucus. Biochem. J. 195:267-275. https://doi.org/10.1042/bj1950267.

Mariscal-Landín, G., B. Sève, Y. Colléaux, and Y. Lebreton. 1995. Endogenous amino nitrogen collected from pigs with end-to-end ileorectal anastomosis is affected by the method of estimation and altered by dietary fiber. J. Nutr. 125:136-146. https://doi.org/10 $.1093 / \mathrm{jn} / 125.1 .136$.
Miner-Williams, W., A. Deglaire, R. Benamouzig, M. F. Fuller, D. Tomé, and P. J. Moughan. 2012. Endogenous proteins in terminal ileal digesta of adult subjects fed a casein-based diet. Am. J. Clin. Nutr. 96:508-515. https://doi.org/10.3945/ajcn.111.033472.

Miner-Williams, W. M., P. J. Moughan, and M. F. Fuller. 2013. Analysis of an ethanol precipitate from ileal digesta: Evaluation of a method to determine mucin. Sci. Rep. 3:3145. https://doi.org/10 $.1038 / \operatorname{srep} 03145$.

Montagne, L., I. Crévieu-Gabriel, R. Toullec, and J. P. Lallès. 2003. Influence of dietary protein level and source on the course of protein digestion along the small intestine of the veal calf. J. Dairy Sci. 86:934-943. https://doi.org/10.3168/jds.S0022-0302(03)73676 -5 .

Montagne, L., R. Toullec, M. Formal, and J. P. Lallès. 2000a. Influence of dietary protein level and origin on the flow of mucin along the small intestine of the preruminant calf. J. Dairy Sci. 83:2820-2828. https://doi.org/10.3168/jds.S0022-0302(00)75181-2.

Montagne, L., R. Toullec, and J. P. Lallès. 2000b. Calf intestinal mucin: Isolation, partial characterization, and measurement in ileal digesta with an enzyme-linked immunosorbent assay. J. Dairy Sci. 83:507-517. https://doi.org/10.3168/jds.S0022-0302(00)74910-1.

Montagne, L., R. Toullec, and J. P. Lallès. 2001. Intestinal digestion of dietary and endogenous proteins along the small intestine of calves fed soybean or potato. J. Anim. Sci. 79:2719-2730. https:// doi.org/10.2527/2001.79102719x.

Montoya, C. A., S. M. Rutherfurd, and P. J. Moughan. 2015. Nondietary gut materials interfere with the determination of dietary fiber digestibility in growing pigs when using the Prosky method. J. Nutr. 145:1966-1972. https://doi.org/10.3945/jn.115.212639.

Nyachoti, C. M., C. F. M. de Lange, B. W. McBride, and H. Schulze. 1997. Significance of endogenous gut nitrogen losses in the nutrition of growing pigs: A review. Can. J. Anim. Sci. 77:149-163. https://doi.org/10.4141/A96-044.

Piel, C., L. Montagne, P. Salgado, and J.-P. Lallès. 2004. Estimation of ileal output of gastro-intestinal glycoprotein in weaned piglets using three different methods. Reprod. Nutr. Dev. 44:419-435. https: //doi.org/10.1051/rnd:2004049.

Santoro, L. G., G. Grant, and A. Pusztai. 1999. In vivo degradation and stimulating effect of phaseolin on nitrogen secretion in rats. Plant Foods Hum. Nutr. 53:223-236. https://doi.org/10.1023/A: 1008025922615.

Schulze, H., H. S. Saini, J. Huisman, M. Hessing, W. Van Den Berg, and M. W. A. Verstegen. 1995. Increased nitrogen secretion by inclusion of soya lectin in the diets of pigs. J. Sci. Food Agric. 69:501-510. https://doi.org/10.1002/jsfa.2740690415.

Stein, H. H., B. Sève, M. F. Fuller, P. J. Moughan, and C. F. M. De Lange. 2007. Invited review: Amino acid bioavailability and digestibility in pig feed ingredients: Terminology and application. J. Anim. Sci. 85:172-180. https://doi.org/10.2527/jas.2005-742.

Tukur, H. M., J. P. Lallès, C. Mathis, I. Caugant, and R. Toullec. 1993. Digestion of soybean globulins, glycinin, $\alpha$-conglycinin and B-conglycinin in the preruminant and the ruminant calf. Can. J. Anim. Sci. 73:891-905. https://doi.org/10.4141/cjas93-091.

\section{ORCIDS}

I. Ansia (1) https://orcid.org/0000-0002-9114-4178

J. K. Drackley (ํ) https://orcid.org/0000-0002-4560-5594 